\title{
Desenvolvimento territorial e escalas geográficas de poder e gestão - o caso da Cooperacana, Porto Xavier-RS
}

\author{
Anelise Graciele Rambo* \\ Aldomar Arnaldo Rückert ${ }^{* *}$
}

\section{Resumo}

Este artigo apresenta uma discussão acerca da temática do desenvolvimento territorial relacionando-o com a questão das escalas geográficas de poder e gestão. Emprega-se o conceito desenvolvimento territorial local/regional, de modo a destacar as relações de poder e gestão sobre um território, numa escala local/regional, bem como sua interação com os atores das demais escalas. Assim, num primeiro momento, será estabelecida uma discussão sobre desenvolvimento territorial além da contribuição da densidade institucional e da inovação territorial coletiva nestes processos. Num segundo momento, esta discussão será relacionada à temática das escalas, e como isso pode contribuir para os estudos referentes à dinâmica territorial do desenvolvimento. Ao final, será apresentado, de forma sintética, um estudo empírico para demonstrar como a metodologia pode auxiliar na compreensão da dinâmica territorial do desenvolvimento.

Palavras-chave: Desenvolvimento territorial local/regional; Escalas geográficas de poder e gestão; Inovação territorial coletiva; Densidade institucional

\footnotetext{
Mestre em Geografia, Doutoranda em Desenvolvimento Rural UFRGS (ane_rambo@yahoo.com.br).

** Professor e Pesquisador dos Programas de Pós-Graduação em Geografia e em Desenvolvimento Rural - UFRGS (aldomar.ruckert@terra.com.br).
}

Geosul, Florianópolis, v. 23, n. 46, p 95-114, jul./dez. 2008 
RAMBO, A.G. \& RÜCKERT, A.A. Desenvolvimento territorial e escalas...

Territorial development and power and management geographic scales- the case of Cooperacana, Porto Xavier-RS

\begin{abstract}
This article presents a discussion concerning the territorial development thematic related to the question of power and management geographic scales. The concept of local/regional territorial development is employed, in order to point out power and management relations of a territory, in a local/regional scale, as well as its interaction with actors of others scales. Thus, at a first moment, it will be established a discussion about territorial development beyond the contribution of institutional thickness and the collective territorial innovation in these processes. In a second moment, this discussion will be related to the geographical scales thematic, and as this can contribute for the studies referring to the territorial dynamics of the development. At last, it will be presented in a synthetic form, an empirical study to demonstrate as the scales methodology can help to understanding of the territorial dynamics of the development.

Key words: Local/regional territorial development; Power and management geographic scales; Collective territorial innovation; Institutional thickness.
\end{abstract}

\title{
Pensando o desenvolvimento territorial com base na inovação territorial coletiva e na densidade institucional
}

A discussão que aqui se pretende estabelecer é proposta numa tentativa de trazer a contribuição da Geografia para os estudos acerca da dinâmica territorial do desenvolvimento. Nesse sentido, buscar-se-á apresentar a metodologia das escalas geográficas de poder e gestão. Entende-se que tal metodologia, aplicada aos estudos de desenvolvimento territorial, permite uma compreensão mais clara de como estes processos são desencadeados, de como os territórios são geridos e quem são estes atores. A partir disso, torna-se possível observar as potencialidades 
RAMBO, A.G. \& RÜCKERT, A.A. Desenvolvimento territorial e escalas...

e debilidades do território as quais podem ser incrementadas ou reduzidas respectivamente, de modo a favorecer os processos de desenvolvimento territorial.

Quando se leva em consideração os reflexos do processo de globalização sobre os territórios, observa-se a emergência e mesmo a reestruturação de espaços hegemônicos e hegemonizados (SANTOS; SILVEIRA, 2004). As disparidades territoriais têm se tornado cada vez mais evidentes no atual estágio do meio técnicocientífico-informacional.

Por sua vez, é importante considerar a multidimensionalidade do poder resultante da descentralização político-administrativa do Estado ocorrida no Brasil a partir dos anos oitenta. Como conseqüência, diferentes atores - Estado, sociedade civil e mercado - atuam sobre o território, estabelecendo relações ora conflituosas, ora sinérgicas. Entende-se que considerar estas relações e estes atores, dentro de um contexto de globalização, torna-se um requisito essencial para a compreensão dos processos de desenvolvimento territorial, pois,

no momento em que se retorna à análise das relações de poder (...) o território volta a ser importante, não mais apenas como espaço próprio do Estado-Nação, mas sim dos diferentes atores sociais, manifestação do poder de cada um sobre uma área precisa (BECKER, 1983, p.7-8).

Para tal entende-se por território o espaço apropriado pelo homem, concreta ou abstratamente, por meio do exercício de relações de poder. Por essa razão concorda-se com Raffestin (1993) quando afirma que o território é produto dos atores sociais, do Estado ao indivíduo, passando por todas as organizações, pequenas ou grandes. São esses atores que produzem o território, composto por nós, malhas e redes.

Nesse sentido, quando se fala em desenvolvimento territorial, entende-se que sejam ações, mecanismos, estratégias e políticas endógenas, desencadeadas por atores locais/regionais em interação com as demais escalas de poder e gestão, reforçando e 
RAMBO, A.G. \& RÜCKERT, A.A. Desenvolvimento territorial e escalas...

constituindo territórios por meio de novos usos políticos e econômicos.

Seguindo nessa perspectiva, entende-se que o desenvolvimento territorial se produz a partir do momento em que os atores, formando uma comunidade/sociedade, se reconhecem como tal e tem como referência primeira seu território. Projetam suas ações sobre suas tessituras, nós e redes, desenvolvendo suas potencialidade (ambientais, humanas, econômicas), constituindo-se como atores mais ativos na intervenção sobre seu território.

Boisier et al (1995) contribui na definição de desenvolvimento territorial. Afirma que o mesmo consiste numa expressão ampla que inclui o desenvolvimento de microlocalidades (comunidades e de meso-localidades, províncias ou regiões). O conceito refere-se a processos de mudança sócioeconômica, de caráter estrutural, delimitados geograficamente e inseridos num marco configurado por sistemas econômicos de mercado, ampla abertura externa e descentralização dos sistemas de decisão. Ou seja, a organização coletiva dos atores locais/regionais, buscando ações, mecanismos, práticas e políticas que visam o desenvolvimento de seu território, com vistas a uma inserção menos subordinada à dinâmica da globalização.

Ainda segundo Boisier et al (1995), o objetivo do desenvolvimento territorial é triplo: (1) o aperfeiçoamento do território entendido não como um container e suporte físico de elementos naturais, mas como um sistema físico e social estruturalmente complexo, dinâmico e articulado; (2) o aperfeiçoamento da sociedade ou comunidade que habita esse território; (3) o aperfeiçoamento de cada pessoa, que pertence a essa comunidade e que habita esse território.

Dessa forma, pode-se considerar que o desenvolvimento territorial objetiva atender as aspirações dos atores locais/regionais. Está voltado à cooperação e à solidariedade e inspira-se nos valores de qualidade e cidadania, incluindo setores marginalizados na produção e usufruto de resultados, não ignorando a questão econômica (SANTOS; SILVEIRA, 2004). Diante desta 
RAMBO, A.G. \& RÜCKERT, A.A. Desenvolvimento territorial e escalas...

consideração, adquirem importância dois conceitos ou duas novas variáveis: a inovação territorial coletiva e a densidade institucional.

A inovação territorial coletiva é entendida como um sistema dinâmico de reprodução territorial fundado em inovações permanentes, resultado de relações de cooperação entre os atores públicos e privados, individuais e coletivos - de determinada região/território (FERNÁNDEZ, 2004). Ou ainda, segundo Méndez, (2002) consiste na capacidade de gerar e incorporar conhecimentos para dar respostas criativas aos problemas do presente, não só em termos de crescimento econômico, mas numa perspectiva integrada.

Considera-se, por sua vez, que a inovação territorial coletiva pode ser gerada por meio da densidade institucional. Esta também caracteriza uma inovação, na medida em que histórico e tradicionalmente predominam ações individualizadas em determinada região ou território.

Assim sendo, a densidade institucional representa a "combinação de fatores, incluindo suas interações interinstitucionais e sinergia, uma representação coletiva por muitos corpos, um objetivo industrial comum e normas culturais e valores compartilhados" (AMIN E THRIFT apud KIRAT; LUNG, 1999, p.31). Fernández (2004), ampliando a discussão de Amim e Thrift, define a densidade institucional como uma sólida presença institucional formal (firmas, associações empresariais, instituições financeiras, ONGs, agências de desenvolvimento, escolas, centros de serviço, institutos tecnológicos e universidades), bem como o desenvolvimento de formas de cooperação entre os atores a partir da consolidação, entre esse complexo de atores, de uma consciência de pertença mútua a uma dinâmica territorial e ao padrão de coalizão representativo dos interesses locais.

Dessa forma, considera-se que os processos de desenvolvimento territorial passam a ser exitosos na medida em que os atores locais/regionais, representados tanto pela sociedade civil, quanto pelo Estado e pelo mercado, buscam estabelecer 
RAMBO, A.G. \& RÜCKERT, A.A. Desenvolvimento territorial e escalas...

ações/projetos/programas, preocupados com a inovação territorial coletiva e com a densidade institucional. Ou seja, inovações construídas de forma coletiva, com base nas potencialidades do território, em interação com as demais escalas de poder e gestão.

Para observar a interação entre atores, acresce-se ao territorial a escala local/regional. A priori, entende-se como desnecessário tal adjetivo, em função do territorial opor-se ao global, e estar subentendida uma dimensão mais local. Porém à medida que se utiliza o recurso metodológico das escalas geográficas de poder e gestão, adota-se "desenvolvimento territorial local/regional" para tornar perceptível a interação dos atores ou dos poderes locais/regionais com as demais escalas de poder e gestão.

\section{As escalas geográficas de poder e gestão}

Considera-se que as escalas geográficas de poder e gestão caracterizam um procedimento metodológico que contribui para a compreensão da dinâmica territorial do desenvolvimento. Esta metodologia permite observar como os atores locais/regionais sociedade civil, Estado e mercado - articulam-se entre si e com as demais escalas de poder e gestão, com vistas à promoção do desenvolvimento de seu território. Considerar-se a existência de diferentes escalas atuantes em determinado território, possibilita a compreensão da densidade e da complexidade oriunda da multiplicidade de poderes neles existentes e atuantes.

A questão da escala vem adquirindo relevância em função do processo globalizador estar deixando o espaço mais dinâmico, mais interconectado. Acaba-se estabelecendo um maior número de fluxos entre os lugares que tendem a assumir um caráter hegemônico ou hegemonizado. Nessa realidade a escala acaba se caracterizando como um método eficiente que, ao estabelecer um subconjunto, torna sua compreensão possível.

Frente à complexidade do espaço, a descrição da totalidade torna-se exaustiva, não levando a compreensão do fenômeno (RAFESTIN, 1993). Racine et al (1983) tratam à escala como um 
RAMBO, A.G. \& RÜCKERT, A.A. Desenvolvimento territorial e escalas...

filtro que empobrece a realidade, mas que preserva o que é pertinente em relação ao objeto ou processo de estudo, permitindo sua compreensão.

Assim, segundo Castro (1995), a escala geográfica pode ser considerada como um artifício analítico que dá visibilidade ao real. Este real, por vezes pode ser compreendido somente através da representação e da fragmentação, um recorte. No entanto, este recorte, visto isoladamente de seu entorno, não tem poder explicativo. Ou seja, o recorte espacial a ser analisado estará sempre relacionado com seu entorno, com as demais escalas.

A multidimensionalidade do poder (Estado, sociedade civil e mercado), também torna a análise da dinâmica territorial mais complexa. Em razão disso, explicar-se o lugar pelo lugar tornou-se algo incoerente. Nem mesmo o lugar pode explicar a totalidade, ou seja, o local não é auto-suficiente e o contrário da mesma forma.

Acselrad (2002) corrobora com a afirmação acima ao mencionar que o processo de desenvolvimento local não pode ser entendido simplesmente como uma resposta endógena aos problemas exógenos ocasionados pela globalização. A dinâmica do desenvolvimento de escala local, se dá pela combinação de fatores em escalas variadas, não havendo um poder econômico estruturalmente local, privado ou público, mas dimensões locais de um poder que se constrói na hierarquia dos tomadores de decisão.

Enfim, a interação entre atores de diferentes escala em prol do desenvolvimento, permite que se atenda as necessidades e demandas dos atores locais/regionais, não restringindo-se aos aspectos econômicos. Em função disso, a densidade institucional assume grande importância, pois reunindo diversos atores públicos e privados, individuais e coletivos - torna-se possível elencar demandas, bem como potencializar especificidades do território, e assim, de forma coletiva, realizar ações concretas promovendo processos de desenvolvimento.

Nesse sentido, Acselrad (2002) novamente traz sua contribuição, ao enfatizar que a escala local atribuída ao desenvolvimento surgiu em função dos resultados negativos do 
RAMBO, A.G. \& RÜCKERT, A.A. Desenvolvimento territorial e escalas...

desenvolvimento de cima para baixo. O desenvolvimento local (ou desenvolvimento territorial local/regional), estaria baseado na realização de projetos concretos, levando em consideração a especificidade do território, o enraizamento dos atores, gerando sinergias locais. Seria acompanhado de uma mudança de mentalidade, caracterizada pela busca do empreendedorismo (ou da inovação territorial coletiva), do pragmatismo em projetos concretos, nas vantagens dos consensos, em novas formas de solidariedade. Como bem lembra o autor, este processo não seria necessariamente mediado pelo Estado, mas pela interação dos atores: sociedade civil, Estado e mercado, de modo a criar coalizões, consensos, evitando a fragmentação de interesses políticos e econômicos, construindo-se um projeto político que atenda as demandas sócio-econômicas do coletivo local.

Frente a isso, surgem alguns desafios aos territórios que pretendem protagonizar seus processos de desenvolvimento: como construir projeto político que de fato atenda as demandas sociais, culturais, econômicas e ambientais locais/regionais? Como conciliar seu projeto ou como articular as diferentes escalas de poder e gestão em torno de um objetivo comum, sendo que por vezes há divergência de interesses entre escalas? De que forma, na escala local/regional, articular os atores, criando uma identidade em torno de um projeto/política, de modo que seja possível constituir sinergias, recursividade?

Considera-se que a busca para responder tais questionamentos, mesmo que não definitiva e conclusivamente, mas ao menos apontando para um caminho, passa pela inovação territorial coletiva e pela densidade institucional. A inovação e a densidade podem juntas, possibilitar o desencadeamento de processos de desenvolvimento territorial local/regional. Isso, à medida que os atores locais/regionais buscam estabelecer consensos reunindo a maior diversidade de atores - públicos e privados, individuais e coletivos -, em torno das potencialidades do território. Quanto a isso, corrobora Méndez (2002), ao afirmar que todas as comunidades territoriais dispõem de um conjunto de 
RAMBO, A.G. \& RÜCKERT, A.A. Desenvolvimento territorial e escalas...

recursos (econômicos, humanos, ambientais, institucionais, culturais...) que constitui seu potencial de desenvolvimento, devendo-se encontrar atores e estratégias capazes de atribuir valor a tais recursos, de forma eficaz e inovadora.

Pelo que foi mencionado, pode-se considerar que os processos de desenvolvimento territorial local/regional, embora apresentem relativo protagonismo dos atores locais/regionais quanto ao exercício de poder e gestão sobre seus territórios, não se mantêm isolados dos atores das demais escalas, podendo-se afirmar que as ações territoriais provavelmente não teriam o mesmo êxito ou resultado se praticadas de forma isolada e individual.

\section{Utilizando a metodologia das escalas em um caso empírico}

A experiência apresentada a seguir é resultado de uma pesquisa de mestrado concluída em 2006. Esta buscou demonstrar como uma cooperativa produtora de álcool combustível, formada por pequenos agricultores do noroeste do Estado do Rio Grande do $\mathrm{Sul} /$ Brasil, desencadeia um processo de desenvolvimento territorial local/regional.

O noroeste gaúcho pode ser considerado periférico, pois encontra-se relativamente distante dos grandes centros industriais e de tomada de decisão do Estado. Além disso, possui sua economia estruturada, de modo geral, em pequenos e médios empreendimentos e na agricultura familiar. Cerca de $70 \%$ dos estabelecimentos rurais da região possuem até 20 ha e a agricultura ainda assume grande participação na constituição do PIB.

Mesmo havendo uma predominância de pequenas propriedades, o cultivo da soja, que tem se tornado economicamente inviável em pequena escala, ainda se destaca na região:

a soja continua sendo o motor econômico regional, porém, não permite a sobrevivência das pequenas e médias propriedades rurais quando vista isoladamente. Os altos custos de produção, a estagnação na baixa dos preços 
RAMBO, A.G. \& RÜCKERT, A.A. Desenvolvimento territorial e escalas...

internacionais da oleaginosa, e a incapacidade destes produtores em assimilarem novas técnicas de comercialização, os obriga a modificarem seu sistema de produção (BRUM, 2002, p.142).

A situação da agricultura não se difere da realidade do espaço urbano da região, e assim, esta acaba não apresentando atratividade econômica ao grande capital. Para tal, parece ser evidente a constatação de que a tendência para os processos de desenvolvimento de regiões periféricas, depende cada vez mais da mobilização e organização das escalas locais/regionais.

Com base no pressuposto acima mencionado, na pesquisa empírica, catalogou-se as inovações territoriais coletivas e mensurou-se a densidade institucional em torno da experiência da COOPERCANA. Ao final da pesquisa, pôde-se observar que a densidade institucional permitiu o desencadeamento de ações com características de inovação territorial coletiva, o que tem atendido a diferentes demandas e necessidades dos atores locais. A partir dessas variáveis, tornou-se possível o desencadeamento de um processo de desenvolvimento territorial local/regional. Seus resultados não se restringiram aos associados da Cooperativa, nem tão somente ao espaço rural, mas a um entorno territorial maior. Essa constatação ficou mais evidente devido ao uso da metodologia das escalas.

\section{COOPERCANA - Cooperativa dos Produtores de Cana de Porto Xavier-RS}

A COOPERCANA, localizada em Porto Xavier, mas com associados também nos municípios de Porto Lucena e Roque Gonzáles, inicia sua trajetória em 1984, quando é constituída a ALPOX S/A (Usina de Álcool de Porto Xavier), incentivada pelo Pró-Álcool. Esta sociedade anônima era composta por 156 acionistas: 143 pequenos agricultores, com 49\% ações e 13 empresários e profissionais liberais detendo $51 \%$ das ações.

Desde sua fundação houve divergências entre sócios majoritários e minoritários, desencadeando-se uma crise financeira 
RAMBO, A.G. \& RÜCKERT, A.A. Desenvolvimento territorial e escalas...

na usina, o que leva a constituição da COOPERCANA. A Cooperativa, que surge na tentativa de contornar essa crise financeira, é composta pelos agricultores produtores de cana e funcionários da usina. Em 1999, por pressão da sociedade civil organizada e por instituições e organizações locais/regionais, o poder judiciário decreta a falência da ALPOX S/A e a COOPERCANA assume os serviços da usina arrendando o parque industrial. A compra do parque pela Cooperativa efetuou-se em setembro de 2004.

Quanto as inovações catalogadas, a primeira a ser destacada refere-se a própria densidade institucional em torno da experiência. Observa-se por parte dos atores envolvidos na Cooperativa, uma busca quanto à interação com demais instituições e organizações, locais/regionais e de outras escalas. Isso permite que sejam atendidas demandas tanto da Cooperativa, quanto do seu entorno territorial maior.

Outra inovação a ser considerada, é o fato de se cultivar cana-de-açúcar numa região onde tipicamente predomina a cultura da soja. O noroeste gaúcho caracteriza umas das maiores regiões produtoras de soja do Estado. Enquanto nos dois COREDEs ${ }^{1}$ (aos quais pertencem os municípios de abrangência da Cooperativa), em 2002 , foram cultivados 657.860 ha de soja, de cana foram apenas 7.212 ha (IBGE, 2005). Esta comparação demonstra que a cultura da cana, comparada à soja, pode ser considerada uma inovação ao nível regional. Tal fato adquire maior importância ao levar-se em conta os problemas de viabilidade econômica do cultivo da soja em pequenas e médias propriedades (BRUM, 2002).

1 A regionalização dos COREDEs - Conselhos Regionais de Desenvolvimento - foi criada pela Lei Estadual n ${ }^{\circ} 10.283$ de 1994, com a finalidade de descentralizar e democratizar as ações de investimento sendo referência para as estruturas administrativas regionais dos órgãos do Poder Executivo. É um fórum de discussão e decisão a respeito de políticas e ações que visam ao desenvolvimento regional com o fim de compatibilizar competitividade, eqüidade e sustentabilidade. Os 497 municípios do Rio Grande do Sul estão distribuídos em 24 COREDEs. 
RAMBO, A.G. \& RÜCKERT, A.A. Desenvolvimento territorial e escalas...

Vale destacar que os atores locais/regionais, aproveitando um micro-clima favorável ao cultivo da cana, idêntico ao tropical ao longo do rio Uruguai, passam a produzir álcool combustível, potencializando um capital tangível e também um intangível. A cana faz parte da cultura regional, sendo cultivada desde época das reduções jesuíticas (1600), porém historicamente, esta é destinada ao auto-consumo nas pequenas propriedades.

Outra inovação é o fato da industrialização da cana e não sua venda in natura, como ocorre no caso da soja. O processo de industrialização aumenta a geração de empregos e impostos na escala local/regional, permite uma remuneração maior dos agricultores, além de ser mais uma fonte de renda para os mesmos.

Pode-se destacar ainda que a Coopercana é a única usina de álcool combustível do Rio Grande do Sul, atendendo a 4\% da demanda do Estado. Sua capacidade de produção chega a 9 milhões de litros/safra, havendo projetos visando ampliação dessa capacidade.

O Estatuto da Cooperativa também assume um caráter inovador, pois dentre os objetivos consta "contribuir para o desenvolvimento regional". Tal objetivo, proveniente de uma organização da sociedade civil e não de alguma instituição do Estado, pode ser considerada uma característica inovadora, uma resposta às demandas e debilidades locais/regionais. Demonstra um comprometimento destes associados para com seu território, não se restringindo a metas corporativas. Pode-se considerar que tal objetivo vem sendo alcançado ao levar-se em consideração os projetos dos quais a Coopercana participa $\mathrm{e}$ as instituições/organizações constituídas a partir da mobilização local.

Por sua vez, para mensurar-se a densidade institucional, catalogou-se os programas/projetos/ações nas quais a COOPERCANA estava envolvida, junto com os demais atores atuantes nos mesmos, destacando a atribuição de cada um.

O estabelecimento das escalas teve por base dois critérios: as divisões político-administrativas, ou escalas institucionalizadas, e escalas não institucionalizadas. Estas últimas são resultantes ou 
RAMBO, A.G. \& RÜCKERT, A.A. Desenvolvimento territorial e escalas...

definidas pela ação/gestão dos atores locais/regionais sobre o território, formando uma identidade ou territorialidade, levando a novos usos políticos e econômicos que tenham reflexos/implicações no desenvolvimento territorial.

Baseando-se nestes critérios, as escalas definidas na pesquisa foram as seguintes: local, delimitada pela localização das propriedades dos associados da COOPERCANA; local/regional, correspondente aos COREDEs Fronteira Noroeste e Missões, regiões onde se localizam os municípios que possuem associados da Cooperativa; além da estadual; federal e internacional.

Após catalogar-se 19 programas/projetos/ações e 51 atores, instituições e organizações da sociedade civil, do Estado e do mercado, pôde-se observar que o número de atores locais/regionais envolvidos é relativamente maior que o das demais escalas. Isso demonstra um comprometimento e protagonismo destes atores quanto à busca por respostas a suas demandas, sendo uma demonstração do poder de organização e gestão destes atores para com seu território. Também é significativa a organização da sociedade civil, somando 20 instituições/organizações presentes na escala local/regional. Por outro lado, o Estado se mostra ativo e atuante, podendo-se dizer até imprescindível, em grande parte dos projetos implementados, realidade que se contrapõe às concepções neoliberais.

Já, para mensurar a densidade institucional, foram estabelecidos quatro níveis. Para tal classificação, é considerada a presença/atuação/participação de atores do Estado, mercado e sociedade civil, das escalas internacional, nacional, estadual, local/regional e local, junto à COOPERCANA, conforme segue:

Tabela 01: Os quatro níveis de densidade institucional

\begin{tabular}{c|l}
\hline Níveis & Poderes presentes/atuantes junto a Coopercana \\
\hline 1 & $\begin{array}{l}\text { Poder federal, estadual, local/regional e local, instituições / } \\
\text { organizações civis e estrangeiras. }\end{array}$ \\
2 & $\begin{array}{l}\text { Poder estadual e instituições/organizações civis. } \\
3\end{array}$ \\
4 & Poder municipal e instituições/organizações civis. \\
\hline
\end{tabular}

Fonte: Baseado em RÜCKERT, 2001. p.538. 
RAMBO, A.G. \& RÜCKERT, A.A. Desenvolvimento territorial e escalas...

Dos 19 programas/projetos/ações das quais a COOPERCANA participa, $53 \%$ são de nível $01 ; 26 \%$ do nível 02 ; e $21 \%$ do nível 04 , não encontrando-se nenhum do nível 03 . Ao levar em consideração que $79 \%$ dos projetos são de nível 01 e 02 pode-se afirmar que há uma alta densidade em torno da experiência, permitindo que estas ações consigam atender a diferentes demandas dos atores locais/regionais envolvidos.

A partir do momento em que os atores locais/regionais e, principalmente, a sociedade civil encontra-se organizada, buscando atender suas demandas e interagindo com atores das demais escalas de poder e gestão - formando uma densidade -, o desencadeamento de um processo de desenvolvimento territorial é possível.

Com base nessa experiência pode-se afirmar que quando o processo de desenvolvimento parte do local, interagindo com as demais escalas, características como legitimidade e democracia se fazem mais presentes, havendo maior participação, comprometimento e identidade destes atores locais para com as ações a serem desenvolvidas.

Vale mencionar ainda que a densidade, permitindo ações inovadoras, possibilita que os atores dêem respostas criativas que não seriam possíveis de serem dadas quando agricultores, empresários e mesmo o poder público, atuam de forma individual. Dessa maneira, torna-se possível atender ou contornar exigências do meio técnico-científico-informacional.

\section{Transformações territoriais: novos usos políticos e econômicos}

A seguir serão apresentadas as transformações territoriais resultantes da densidade institucional e da inovação territorial coletiva expressas por meio de novos usos políticos e econômicos do território. 
RAMBO, A.G. \& RÜCKERT, A.A. Desenvolvimento territorial e escalas...

\section{Os novos usos políticos}

A constituição da COOPERCANA já é resultado da interação e cooperação entre diferentes instituições e organizações locais/regionais. Para sua criação foi necessário um grande apoio da ASTRF $^{2}$, STR-Porto Xavier, igrejas católica e evangélica e $\mathrm{COOPAX}^{3}$. Isso pois os plantadores de cana e os funcionários da ALPOX S/A estavam desmotivados em dar continuidade às atividades da usina, sendo estes atores fundamentais no processo de mobilização dos funcionários e agricultores para a criação da Cooperativa.

Por sua vez, a partir da COOPERCANA, foram criadas outras instituições/organizações, as quais interagem freqüentemente em diversos projetos e ações. Assim sendo, podese citar a Coopercil-Cooperativa dos Recicladores (nível de densidade 02); uma agência bancária do Sistema CRESOL ${ }^{4}$ (nível $01)$; o Ensino Médio Alternativo, voltado à realidade rural do município (nível 02); a rádio comunitária Amizade FM (nível 04); bem como a AREDE - Associação Regional de Educação, Desenvolvimento e Pesquisa (nível 04). Outro uso político parte de projetos financiados pela COOPERCANA através da Lei de Incentivo à Cultura (nível 02).

A formação destas instituições/organizações demonstra que os reflexos da Cooperativa não se dão apenas no espaço rural. Expandem-se de forma territorial, incluindo o espaço urbano e regional, gerando transformações territoriais mais significativos à medida que esta interage com demais atores de diferentes escalas.

\section{Os usos econômicos do território}

O uso econômico que mais se destaca é o próprio cultivo da cana-de-açúcar. De 1999 a 2005 houve um incremento de 64\% ou 800 ha na área cultivada com cana. Valor significativo considerando que em média as propriedades possuem 20 ha. Além

\footnotetext{
${ }^{2}$ Associação dos Sindicatos dos Trabalhadores Rurais Fronteiriços.

${ }^{3}$ Cooperativa dos Pequenos Agricultores de Porto Xavier.

${ }^{4}$ Sistema Integrado de Cooperativas de Crédito Rural com Interação Solidária.
} 
RAMBO, A.G. \& RÜCKERT, A.A. Desenvolvimento territorial e escalas...

disso, a própria industrialização da cana e sua transformação em álcool combustível caracteriza um novo uso econômico, pelo fato de se tratar da única usina de álcool do Rio Grande do Sul.

Além do mais, nos 6 anos de atividades da COOPERCANA, esta recolheu quase R\$ 7 milhões em impostos. É importante destacar ainda que a Cooperativa é responsável por $50 \%$ ICMS recolhido no município. Pode-se ressaltar assim que os impostos recolhidos pela Cooperativa podem levar a diferentes transformações territoriais, beneficiando pessoas que não possuem ligação direta com a usina.

Outro novo uso econômico observável é a geração de 919 empregos e postos de trabalho. Estes provenientes de uma usina de álcool, localizada em uma região conhecida como Berço Nacional da Soja, podem ser considerados um novo uso econômico.

Além das transformações territoriais citadas, pode-se elencar alguns projetos que vem sendo desenvolvidos. Estes, da mesma forma levam a novos usos econômicos do território, na medida em que tem disseminado a cadeia da cana-de-açúcar. São eles: "Estudo de adaptação de Variedades de Cana-de-açúcar na Região Noroeste do Rio Grande do Sul", (nível 01); Rede de Cidades (nível 01), que consistia em constituir um plano de ações para o desenvolvimento e combate à pobreza, a partir de propostas de projetos já existentes na região. Resultado do Rede de Cidades, pode-se citar o projeto "Construindo Segurança Alimentar nas Missões do RS - gerando renda e saboreando alimentos com a cultura da cana-de-açúcar na agricultura familiar"; além de haver projetos relacionados ao Programa Nacional de Produção e Uso do Biodiesel (densidade 01) e ainda "Modernização da Planta Industrial na Produção de Álcool para Produção de Biodiesel pela Agricultura Familiar"(nível 01). Estes projetos incentivam a diversificação produtiva, a pluriatividade e as práticas agroecológicas, tendo como ponto de referência a cultura da cana-de-açúcar.

Pelo que foi mencionado, ainda que muito resumidamente, pode-se observar que os projetos e ações acima descritos apresentam características inovadoras frente à realidade 
RAMBO, A.G. \& RÜCKERT, A.A. Desenvolvimento territorial e escalas...

local/regional, além de uma considerável densidade institucional. Isso permite que, a partir da iniciativa dos atores locais/regionais, $\mathrm{e}$ da busca da interação com demais atores das diferentes escalas de poder e gestão, seja possível atender algumas das demandas e necessidades locais/regionais. Tais projetos/ações acabam tendo um reflexo territorial e não setorial, justamente em razão das diferentes instituições e organizações que participam dos mesmos.

\section{Considerações finais}

Enfim, entende-se que a adoção das escalas geográficas de poder e gestão como recurso metodológico, possibilita a observação de quais poderes ou atores atuam sobre o território, possibilitando assim, compreender-se a importância e a contribuição de cada um na promoção de processos de desenvolvimento. Torna-se possível assim, observar as repercussões territoriais de cada escala em um micro-território ou na escala local/regional.

A metodologia escalar evidenciou a importância da mobilização e organização da escala local/regional. Grande parte dos programas/projetos/ações desenvolvidos, partiu de necessidades e iniciativas locais, as quais acabaram buscando suporte em programas ou mesmo ações das demais escalas. Ou seja, os problemas e as demandas partem dos atores locais, os quais procuram o apoio dos atores das demais escalas, sejam do Estado, da sociedade civil ou mesmo do mercado.

Nesse sentido pode-se apontar que a gestão territorial do desenvolvimento deve estar ancorada em uma alta densidade institucional, em ações inovadoras com base na potencialização das especificidades territoriais. Torna-se essencial, atores locais organizados em torno de suas demandas, procurando respostas a estas em diferentes escalas. Enfim, macro e micro poderes não são excludentes, muito pelo contrário. Ao formarem uma densidade, superam conflitos e estabelecem relações de sinergia e de concertação, fortalecendo-se mutuamente.

Dessa forma, entende-se que quando ações que visam o desencadeamento de processos de desenvolvimento territorial 
RAMBO, A.G. \& RÜCKERT, A.A. Desenvolvimento territorial e escalas...

partem dos atores locais, buscando interagir com as demais escalas de poder e gestão, formando uma sinergia, tal processo gera resultados mais imediatos, concretos e contínuos. Já a metodologia das escalas, permite que se observe a dinâmica dos atores, quais estão presentes neste processo, qual o papel de cada um, quais atores devem ser integrados à dinâmica para minimizar as debilidades territoriais existentes e potencializar as especificidades.

Enfim, a análise escalar constitui um método não dicotômico de apreensão da realidade. O método leva em consideração elementos ou atores distintos mas imbricados, que empregam novos usos políticos e econômicos do território. Cada ator possui sua territorialidade, e o recurso das escalas recupera a importância dos atores relegados a posições coadjuvantes nas análises centradas no marco estatal, atribuindo relevância a várias dimensões que interconectadas, influenciam na dinâmica territorial. Neste sentido pode-se trazer uma última contribuição de Castro (2006, p.7) acerca de três pressupostos que podem então ser estabelecidos acerca das escalas: (1) não há escala mais ou menos válida, a realidade está contida em todas elas; (2) a escala da percepção é sempre ao nível do fenômeno percebido e concebido e (3) a escala não fragmenta o real, apenas permite a sua apreensão. A escala, pode ser entendida assim, como um instrumento que possibilita investigar a dinâmica territorial do desenvolvimento.

\section{Referências bibliográficas}

ACSELRAD, Henri. Território e Poder: as políticas das escalas. In: FISHER, Tânia (org). Gestão do Desenvolvimento e Poderes Locais: marcos teóricos e avaliação. Salvador: Casa da Qualidade, 2002.

BECKER, Berta K. O Uso Político do Território: questões a partir de uma visão do terceiro mundo. In: BECKER, K.; COSTA, K.; SILVEIRA, B.; (orgs) Abordagens Políticas da Espacialidade. Rio de Janeiro: UFRJ, 1983. 
RAMBO, A.G. \& RÜCKERT, A.A. Desenvolvimento territorial e escalas...

BOISIER, Sergio; LIRA, Luis; QUIROGA, Bolivar; ZURITA, Gladys; ROJAS Claudio. Sociedad Civil, Actores Socielies y Desarrollo Regional. Santiago do Chile: Ilpes/Cepal, 1995.

BRUM, Argemiro Luis. A Economia Mundial da Soja: impactos na cadeia produtiva da oleaginosa no Rio Grande do Sul 1970-2000. Ijuí: Unijuí, 2002.

CASTRO, Iná E. de. O Problema da Escala. In: Geografia Conceitos e Temas. Rio de Janeiro: Bertrand-Brasil, 1995.

. Do espaço político ao capital social. O problema da sobre representação legislativa nos municípios pequenos. In: Seminário Internacional sobre Desenvolvimento Regional. 3, 2006, Santa Cruz do Sul. Anais, Santa Cruz do Sul: Unisc, 2006.

FERNÁNDEZ, Víctor Ramiro. Densidad Institucional, Inovación Colectiva y Desarrollo de las cadenas de valor local: un triángulo estratégico en la evolución de los enfoques regionalistas durante los '90s. In: Revista Redes. Santa Cruz do Sul: v.9, nº 1, jan/abr, 2004.

FEE. Fundação de Economia e Estatística. Disp. em: www.fee.tche.br. Acesso em set/05

HAESBAERT, Rogério. Desterritorialização: entre as redes e os aglomerados de exclusão. In: CASTRO, I.; GOMES, P.C.C.; CORREAA,R. L. (orgs). Geografia Conceitos e Temas. Rio de Janeiro: Bertrand-Brasil, 1995.

IPD - Instituto de Políticas Públicas e Desenvolvimento Regional. Núcleo do Banco de Dados. Disponível em: $<$ http://seguro.unijui.tche.br/nbd/>. Acesso em: jan/2005; maio/2005.

KIRAT, T.; LUNG, Y. Inovation and Proximity. Territories as loci of collective learnig process. In: European Urban and Regional Studies. London, vol.6, $\mathrm{n}^{\circ} 1,1999$. 
RAMBO, A.G. \& RÜCKERT, A.A. Desenvolvimento territorial e escalas...

LEADER. Capital Territorial e Projeto do Território. Disponível em: <http://europa.eu.int/comm/archives/ leader2/ruralpt/biblio/coll/art08.htm>. Acesso em: maio/2005.

MÉNDEZ, Ricardo. Innovación y desarrollo territoril: alguns debates teóricos recientes. Eure. Santiago: vol. 28, n ${ }^{\circ} 84,2002$, Disponível em www.scielo.cl/scielo.php. Acesso em 12/07/04.

NASCIMENTO, Décio Estevão do. Desenvolvimento Regional e Redes de Difusão de Tecnologia. In: Seminário Internacional sobre Desenvolvimento Regional. 2, 2004, Santa Cruz do Sul. Anais, Santa Cruz do Sul: Unisc, 2004.

RACINE, J.B.; RAFFESTIN, C.; RUFFY, V. Escala e Ação: contribuições para uma interpretação de mecanismo de escala prática da geografia. In: Revista Brasileira de Geografia. vol 45, nº 1 , jan-mar, 1983.

RAFFESTIN, Claude. Por uma Geografia do Poder. São Paulo: Ática, 1993.

RAMBO, Anelise G.. A Contribuição da Inovação Territorial Coletiva e da Densidade Institucional nos Processos de Desenvolvimento Territorial Local/Regional: A experiência da Coopercana - Porto Xavier/RS. Porto Alegre: Universidade Federal do Rio Grande do Sul: Dissertação (Mestrado em Geografia), 2006.

RÜCKERT, Aldomar A. Reforma do Estado e Tendências de Reestruturação Territorial. Cenários contemporâneos no Rio Grande do Sul. São Paulo: Universidade de São Paulo: Tese (Doutorado em Geografia Humana), 2001.

SANTOS, M.; SILVEIRA, M.L. O Brasil: território e sociedade no início do século XXI. 6.ed., Rio de Janeiro: Record, 2004. 